\title{
SPINAL CORD INJURIES IN DOGS PART I: A REVIEW OF BASIC KNOWLEDGE
}

\author{
Šulla, I. ${ }^{1}$, Balik, V. ${ }^{2}$, Horňák, S. ${ }^{3}$, Ledecký, V. ${ }^{3}$ \\ ${ }^{1}$ Department of Anatomy, Histology and Physiology \\ ${ }^{3}$ Small Animal Clinic, University of Veterinary Medicine and Pharmacy \\ Komenského 73, 04181 Košice \\ Slovakia \\ ${ }^{2}$ Institute of Molecular and Translational Medicine \\ University Hospital and Faculty of Medicine and Dentistry \\ Palacky University, I. P. Pavlova 6, 77220 Olomouc \\ Czechia
}

igor.sulla@uvlf.sk

\section{ABSTRACT}

Spinal cord injuries (SCI) in dogs are not frequent, but they are serious pathological conditions accompanied with high morbidity and mortality. The pathophysiology of SCI involves a primary insult, disrupting axons, blood vessels, and cell membranes by mechanical force, or causes tissue necrosis by ischemia and reperfusion. The primary injury is followed by a cascade of secondary events, involving vascular dysfunction, edema formation, continuing ischemia, excitotoxicity, electrolyte shifts, free radical production, inflammation, and delayed apoptotic cell death. The most frequent cause of SCI in dogs is an acute intervertebral disc extrusion, exogenous trauma or ischemia. Neurological symptomatology depends on the location, size and the type of spinal cord lesions. It is characterized by transient or permanent, incomplete or complete loss of motor, sensory, autonomic, and reflex functions caudal to the site of the lesion. In a case of partial spinal cord (SC) damage, one of the typical syndromes develops (e. g. Brown-Séquard syndrome, central SC syndrome, ventral SC syndrome, dorsal SC syndrome, conus medullaris syndrome, or traumatic cauda equina syndrome). The severe transversal spinal cord lesion in the cervical region causes paresis or plegia of all four extremities (tetraparesis, tetraplegia); in thoracic or lumbosacral region, paresis or plegia of the pelvic extremities (paraparesis, paraplegia), i.e. sensory-motor deficit, urinary and foecal incontinence and sexual incompetence. The central nervous system in mammals does not regenerate, so the neurological deficit in dogs following severe SCI persists for the rest of their lives and animals display an image of permanent suffering. The research strategy presented here involved a PubMed, Medline (Ovid) and ISI Web of Science literature search from Januray 2001 to December 2017 using the term "canine spinal cord injury" in the English language; also references from selected papers were scanned and relevant articles included.

Key words: dog; pathophysiology; spinal cord injury; symptomatology 


\section{INTRODUCTION}

A spinal cord injury (SCI) is defined as damage to the spinal medulla (a traumatic medullopathy, i.e. TM) inflicted by a mechanical insult or ischemia $[10,11,21]$. The annual incidence of SCIs is relatively low (3-5/100000 in humans, much lower in animals), but they are devastating neurological disorders, remaining important causes of morbidity and mortality [14, 23, 30, 36, 39]. Survivors often have major sequelae, including tetra- or paraparesis, eventually tetra- or paraplegia, urinary and fecal incontinence, sexual incompetence and are partially or completely physically dependent for the rest of their lives [3, 14, 30, 42, 55]. The neurological deficit in SCI develops through two pathological events - the primary and secondary damage $[4,16,41]$. The primary injury encompasses the immediate lesion to the spinal cord tissue that occurs at the moment of insult, which is irreversible and not preventable $[46,56]$. The secondary injury develops as a result of the pathological processes initiated at the time of the primary event, continues for several days and even months after trauma and is amenable by therapy $[13,24,39,40,56]$. The clinical outcome in individuals with SCIs is determined by the location and size of the neural tissue damage, age of a patient and associated complications $[3,27,42,50]$. The most frequently observed causes of acute SCIs in humans are traffic accidents, falls and sport injuries. Spinal cord traumatic incidents are reported in domestic animals, especially in dogs, too $[10,11,14,48]$. The irreversible loss of functions due to the damage of the spinal cord tissue has been recognised for centuries, but only limited therapeutic options are available until the present time $[1,2,8,31]$. So the management of SCIs in humans as well as in other animals is basically targeted at preservation of remaining functions and prevention of complications; especially pulmonary and urinary tract infections, spasticity and pressure sores, i. e. decubitus $[3,14,23,27,39,50]$. In spite of a specialised attendance and application of different therapeutic interventions, the neurological deficit in a dog following serious SCI does not improve and it displays an image of permanent suffering for the rest of the dog's life (Fig. 1).

The ambition to improve the unfavourable situation inspired the authors to review recently published studies related to SCIs in small laboratory animals, in dogs and pigs as well as in humans and translate the recent information to everyday clinical practices [4-7, 16-18, 36, 52].

\section{Basic anatomical and physiological facts}

The brain (cerebrum) and spinal cord (medulla spinalis) constitute the central nervous system (CNS). The brain is enclosed within the skull (cranium), the spinal medulla within the vertebral canal (canalis vertebralis). The spinal cord is a direct continuation of the brain stem (medulla oblongata, myelencephalon). It has two enlargements (intumescentia cervicalis giving origin to the nerves of plexus

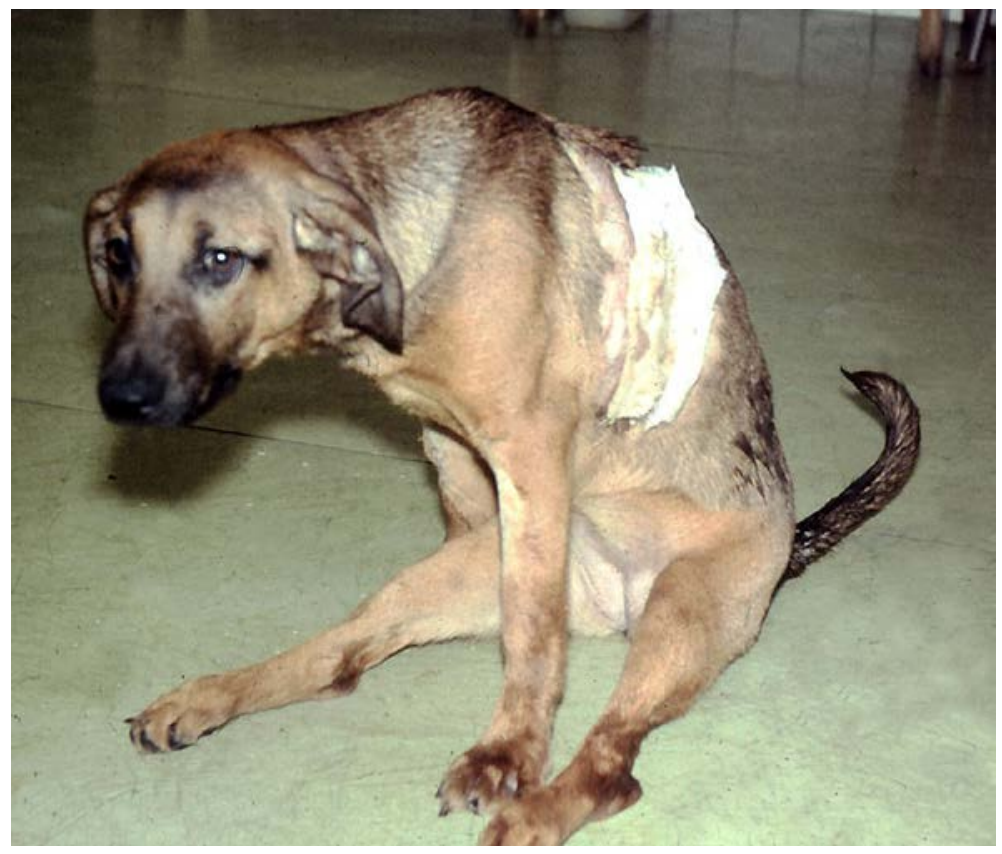

Fig. 1. Dog with ischemic paraplegia due to 30-min. of thoracic aorta cross-clamping 
brachialis and intumescentia lumbalis - the origin of plexus lumbosacralis). The spinal medulla in dogs has a total 36 segments ( 8 cervical, 13 thoracic, 7 lumbar, 3 sacral and 5 caudal) and it extends from the 1st cervical nerves to the caudal part of an elongated cone (conus medullaris) consisting of spinal cord segments S2, S3, Ca1 to Ca5 [19, 20]. The sacral and caudal segments appear successively smaller and they are surrounded by caudally directed spinal roots [19]. About $1 \mathrm{~cm}$ caudal to the last segment (spinal cord termination), the medulla is reduced to a strand of glial and ependymal cells called terminal filament (filum terminale). The development of the spinal cord (medulla spinalis) begins in the canine embryo soon after the post-somite phase, when the cord reaches into the coccygeal part of the vertebral canal. In later developmental stages, the bones and cartilages of the vertebral column grow more rapidly than the cord itself. The disproportional growth of these structures as well as the difference in length of the individual spinal cord segments cause cranial "shift" of the spinal cord termination [20]. The caudalmost pairs of lumbar (L6 and L7), all sacral (S1-S3) and caudal/coccygeal (Cd/Cco1-5) spinal roots continue within the vertebral canal to corresponding intervertebral foramina $[19,20]$. The structure resembles the tail of a horse, so the anatomic nomenclature adresses it as the cauda equina (CE). Skeletotopic localisation of the medullary cone depends on the breed of the animal. In giant dogs it is located at the mid-body of the 6th lumbar vertebra, in big dogs at the L6/L7 intervertebral space, in intermediate sized dogs at the L7/S1 intervertebral space, in small dogs at the level of the S1 vertebra [19, 20]. The basis for dividing the spinal cord into segments are the attachments of the nerve roots. Each dorsal or ventral nerve root (radix dorsalis, radix ventralis) is composed of thousands of axons. The axons of every root are bound together laterally where dorsal and ventral roots join to form the spinal nerve, but as roots approach the spinal cord, their axons regroup into separate bundles called rootlets (fila radicularia) attaching serially along the spinal cord. At the level of the intervertebral foramen, the spinal roots join and become a spinal nerve. At the terminal parts of the dorsal nerve roots (just before their junctions with the ventral nerve roots) are located aggregations of pseudounipolar neurons named spinal ganglia (ganglia spinalia). The pseudounipolar cells deliver central and peripheral processes. The central processes form the dorsal root filaments (sensitive), the peripheral processes intermingle with the axons of the ventral root filaments (motoric) in forming the main trunk of the spinal nerve containing both, sensory and motor fibres. The spinal cord and spinal roots inside the vertebral canal are enveloped by three protective layers termed meninges. The superficial layer (dura mater) is fibrous and thick. It forms a cylinder surrounding the spinal medulla and through lateral extensions it (together with arachnoidea and pia mater) ensheathe spinal roots. The thin arachnoid membrane also lines the inner surface of the dura mater. A subarachnoid space containing the cerebrospinal fluid (CSF) is located

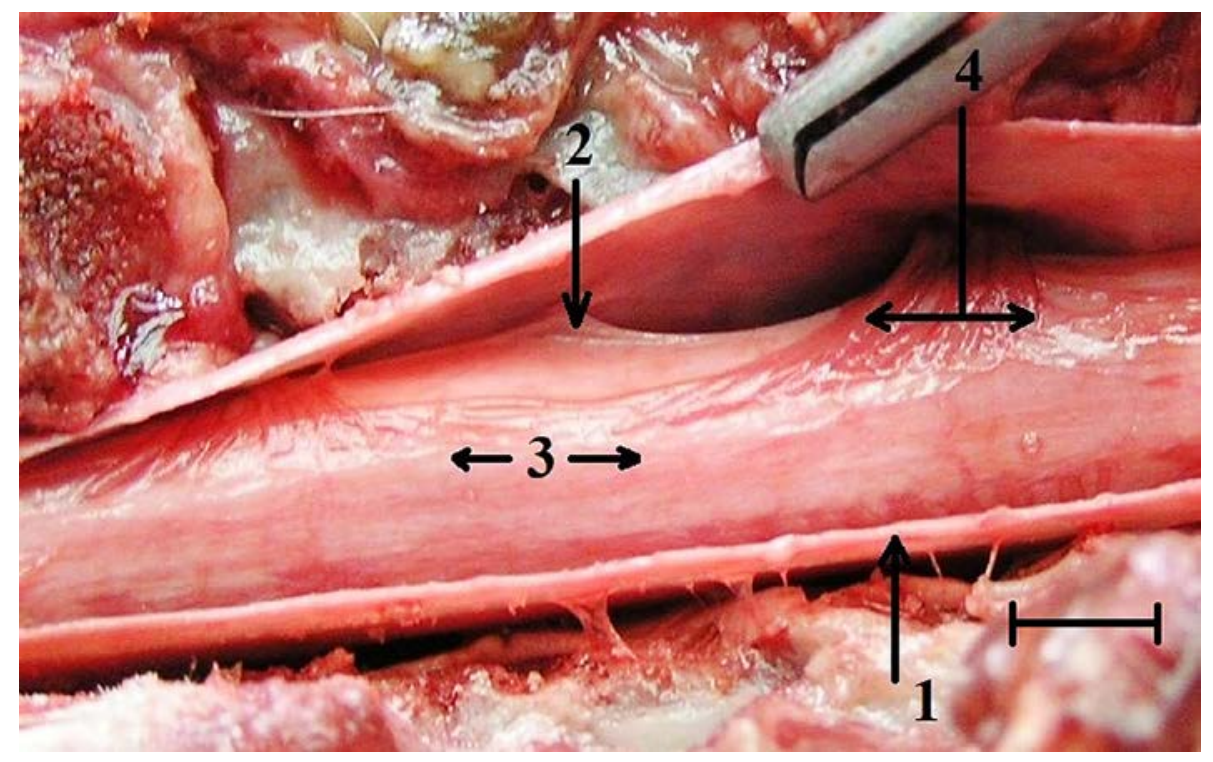

Fig. 2. An anatomical specimen of canine spinal cord after laminectomy and durotomy

1 - dura mater spinalis; 2 - dental ligament; 3 - spinal medulla covered by arachnoidal membrane and pia mater; $4-$ spinal nerve roots. Bar $=5$ mm 
below the arachnoid membrane (Fig. 2). The pia mater, the deepest, most vascular meninx, is bound to glial cells at the spinal cord surface [20].

\section{The spinal cord performs three main functions:}

1. Via spinal nerve connections it processes afferent (centripetal) information from muscles, tendons, joints, ligaments, blood vessels, skin and viscera, and discharges efferent (centrifugal) commands controlling muscles and regulates glands.

2. The spinal cord is a reflex center producing subconscious responses of muscles and glands to specific stimuli.

3. The spinal cord conducts and modifies information to and from the brain through a system of axonal tracts by which the brain receives informations from peripheral organs and tissues while dispersing commands that control posture, movement and the visceral aspects of behaviour $[14,19,20]$.

\section{Etiology of SCI in dogs}

The most common causes of acute spinal cord damage (myelopathy) in dogs is an extrusion of material from the central part of the disc (nucleus pulposus) into the spinal canal due to intervertebral disc degenerative changes (Hansen type I disc disease), exogenous traumatic events and infarction due to ischemia $[9,10,11,22,23,33]$.

Degenerative disc disease is a common problem in dogs, but relatively rare in cats $[14,33,35,39]$. There are two basic types of intervertebral disc diseases, referred to as chondroid and fibroid degeneration. In chondroid degeneration, the normally gelatinous pulpous inner part of disc (nucleus pulposus) undergoes degradation of glycosaminoglycan components and loses its water-binding capacity. The abnormal contents of the nucleus pulposus herniate (extrude) through the thinner dorsal part of the external fibrous ring of the disc (annulus fibrosus) into the vertebral canal. This type of canine intervertebral disc disease (IVDD) is called Hansen type I IVDD and most frequently is seen in chondrodystrophic breeds of dogs (e.g. Basset Hounds, Beagle, Dachshund, Shi Tzu, Lhasa Apso). The Hansen I type of IVDD is characteristicly a sudden rupture of the dorsal part of the annulus fibrosus with an explosive release of the nucleus pulposus material. It causes concussion or compression of the spinal medulla and results in varying degrees of neurological dysfunctions [22, 33, 39]. The severity of the spinal cord damage caused by type I disc extrusion is related to the rate of herniation (force of impact), the duration of neural structure's compression and the volume of the extruded disc material. The incidence of dogs presenting with neurological symptoms due to intervertebral disc herniation is about $2 \%$ of all cases admitted to veterinary facilities $[9,23,39,48]$.

The second most frequent cause of SCIs in dogs is trauma. It usually occurs in association with traffic accidents, vertical falls, animal-animal or human-animal interactions, gunshot or stab wounds and usually accompany vertebral fractures or luxations. At present, about $60 \%$ of traumatic SCIs in dogs are the consequences of traffic accidents [10, 14, 39].

Fibrocartilaginous (FCE) embolism is a rare cause of an acute spinal cord dysfunction [11, 35, 43, 59]. It is induced by the occlusion of spinal vasculature (leptomeningeal and intramedullary vessels) by material from the nucleus pulposus producing ischemia of dependent region of the spinal cord parenchyma. The clinical presentation is of a peracute, non-progressive paralysis with a distribution and severity depending on the site of the infarction. Since the definitive diagnosis of FCE is not possible without histological examination, diagnostic procedures should exclude compressive myelopathy, particularly that caused by intervertebral disc herniation $[9,23,32,48]$. The true incidence of FCEs is difficult to assess; the condition predominantly affects dogs of big and giant breeds $[11,21,35,43,60]$.

\section{Clinical presentation}

The neurological deficit characteristics for spinal cord injury depends upon the location, size and the rate of development of the lesion $[14,23,24,55]$. The signs of spinal cord trauma are typically acute and may further progress in instances of unstable fractures or luxations [14, 39]. A severe medullary damage may cause paraplegia with increased extensor tone in the thoracic limbs. The symptom is called Schiff-Sherrington phenomenon [45]. A small unilateral damage of the spinal medulla will likely cause symptoms predominantly on the side of the lesion. Large lesions or lesions associated with substantial cord swelling will result in the development of bilateral symptomatology $[39,54,55]$.

A benign spinal cord injury, when the traumatic forces cause functional derangement of spinal cord circuits only, but no mechanical disruption of the medulla or its tracts, is called spinal cord concussion (Commotio medullae spi- 
nalis). It belongs to the so called mild spinal traumas and in a majority of the cases it is inflicted by a blow to the vertebral column [49]. It leads to transient paresis, but the patient never reveals symptomatology of a complete (transversal) spinal cord lesion $[14,45]$.

In case a partial medullary damage develops, one of the syndromes results in an incomplete spinal cord lesion $[14,34,56]$. The clinical symptomatology of an incomplete medullary lesion is given by their anatomic relationships, i. e. by the course of motor and the sensitive tracts and the location of the spinal cord vessels. If the whole spinal medulla is mechanically or functionally damaged, the situation is termed a transversal spinal cord lesion. In this situation neurological examination reveals a complete loss of motor, sensitive and vegetative functions caudally from the epicentre (Fig. 2). It is important to stress, that immediately after spinal trauma even patients with incomplete medullary lesions reveal transient supression or loss of muscle tone and segmental spinal reflexes caudal to the SCI. This phenomenon is called spinal shock, which differs essentially from the neurogenic shock [15, 31, 47]. Compared with big apes and humans, where spinal shock resolves in a series of phases extending over days to weeks, the recovery from the spinal shock in non-primates is relatively rapid (e.g. the patellar reflex in rabbits reappears $10-15$ minutes following SCI, between 30 minutes and 2 hours in cats and dogs); it does not attract the major attention of veterinarians, so far $[47,55]$. In an acute phase of SCI, the gross reactions of the organism are characterised by tachycardia, later on it is replaced by bradycardia; blood pressure fluctuates, too - the initial hypertension is later on substituted by hypotension $[55,56]$. The peripheral vascular resistance declines, the cardiac output is diminished, blood levels of cathecholamines increase, and then subsequently decrease. In the case of cervical SCIs, the respiration is endangered and dogs succumb or are euthanized at the place of the event $[14,24,34,39,44]$.

Spinal cord hemisection syndrome (Brown-Séquard syndrome or BSS) occurs when just one side of the spinal medulla is damaged or it is injured much more severely than the other. It is rare to see the spinal cord truly hemisected, much more frequently it is called Brown-Séquard plus syndrome or partial lesions due to the penetrating injuries (e.g. gunshot or stab wounds) or vertebral fractures and luxations (Fig. 3).

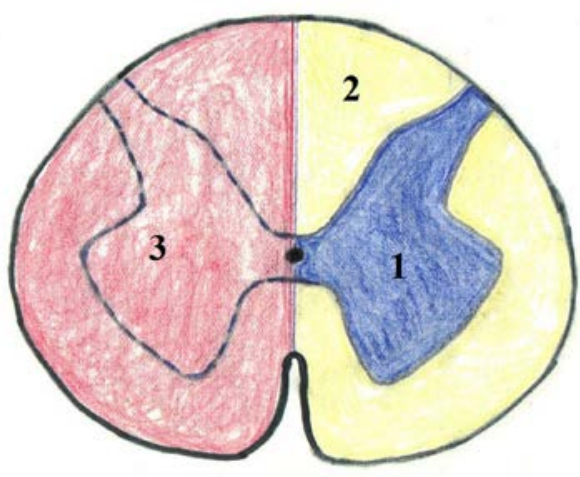

Fig. 3. Schematic representation of spinal cord hemisection syndrome, i. e. Brown-Séquard syndrome (BSS)

1 - gray matter; 2 - white matter; 3 - lesioned part of spinal cord (pink area)

On the ipsilateral side of the lesion, the body loses motor functions, proprioception, the sense of vibration and touch. On the contralateral side of the injury pain and temperature sensations are lost $[14,34]$.

Central spinal cord syndrome (central cord syndrome or CCS) usually results from the damage to the cervical part of the spinal medulla due to the neck hyperextension in patients with cervical spinal stenosis (Fig. 4).

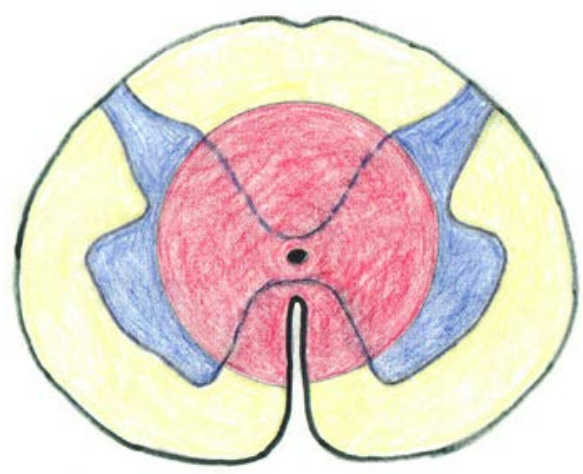

Fig. 4. Schematic representation of a central spinal cord syndrome (CCS) (pink area)

The CCS is characterized by weakness in the thoracic extremities with relative sparing of the pelvic extremities and loss of sensation of pain, temperature, light touch, and pressure caudal to the level of injury [14]. The spinal tracts that serve thoracic limbs are more affected due to their central location in the spinal cord, while the corticospinal fibers destined for the pelvic limbs are spared due to their more external location $[14,34]$.

Ventral spinal cord syndrome (ventral cord syndrome or VCS) is caused by damage to the ventral portion of the spinal medulla or the reduction in the blood supply from the ventral spinal artery (Fig. 5) compressed by fragments 
of vertebral bodies or herniated intervertebral discs [10, 14, 34]. The VCS is characterized by urinary retention, loss of motor functions, pain and temperature sensation caudal to the level of injury, while the sense of touch and position in space remains intact $[14,34,39]$.

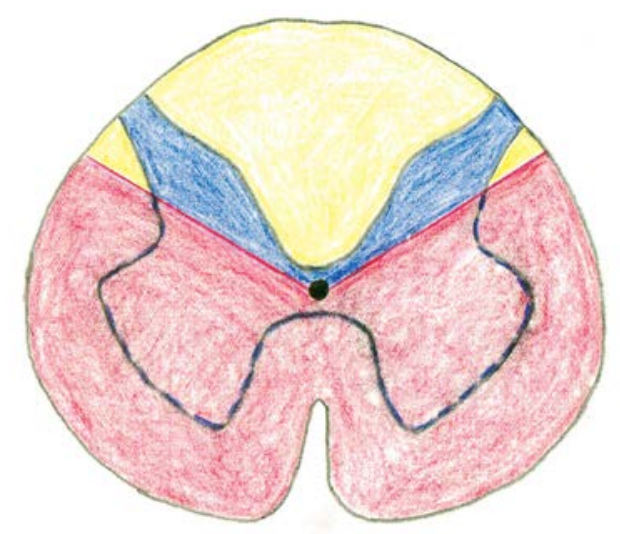

Fig. 5. Schematic representation of a ventral spinal cord syndrome (VCS) (pink area)

Dorsal spinal cord syndrome (dorsal cord syndrome or DCS), in which the dorsal columns of the spinal medulla are affected (Fig. 6), is usually seen in patients with vertebral canal degenerative stenosis or infarction of the posterior spinal arteries $[14,34,39]$. The DCS is characterized by the loss of proprioception and the sense of vibration caudal to the level of the lesion, while motor functions and the sensation of pain, temperature, and touch remain intact $[14,34]$.

Conus medullaris syndrome (CMS) is caused by an injury to the caudal end of the spinal medulla [14]. This region is responsible for bowel, urinary bladder and sexual functions; perianogenital and tail sensation. The Achilles tendon reflex can be affected also. The symptoms occur bilaterally $[14,34,55]$.

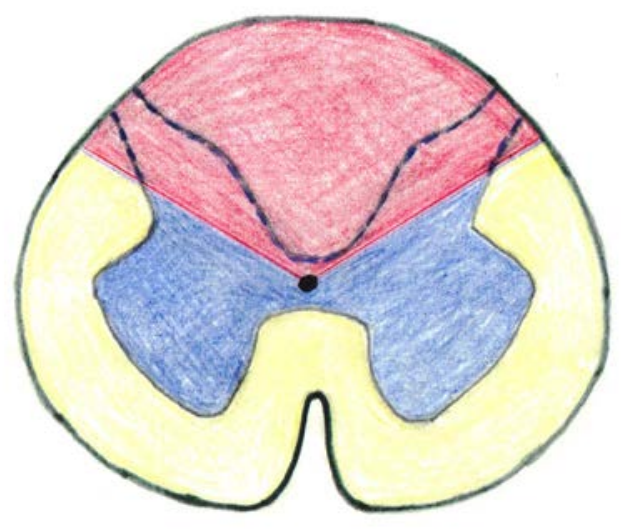

Fig. 6. Schematic representation of a dorsal spinal cord syndrome (DCS) (pink area).
Traumatic cauda equina syndrome (cauda equina syndrome or CES) results from a lesion to L7-Cd5 spinal nerve roots due to the fracture and dislocation of the sacral bone or L7/S1 intervertebral disc herniation [14, 34, 39]. It is not a true spinal cord syndrome, since the spinal cord nerve roots damaged in CES are actually peripheral nerves. The CES can occur by itself or alongside with the CMS. It is characterized by: low back pain, weakness in the pelvic extremities, nociceptive deficits in the medial areas of the pelvic limbs, perineum and tail, and bowel and urinary bladder dysfunctions $[14,34]$. Unlike the conus medullaris syndrome, symptoms of CES often occur unilaterally (Fig. 7).

\section{Pathophysiology of spinal cord injury}

The damage in SCIs begins suddenly at the moment of a traumatic event when displaced vertebrae, their fragments, intervertebral disc material or ligaments compress or tear the spinal medulla and its blood vessels $[4,10,14$, 16]. External forces sever axons and blood vessels which causes hemorrhage (predominantly in the gray matter) and ischemia $[16,18,26,37,41]$. Within several minutes the spinal cord swells and fills the spinal canal $[16,37,41$, $44,61]$. The increased compression of vessels diminishes blood flow, decreases medullary tissue oxygen supply and enhances ischemia. The situation further deteriorates due to systemic blood pressure drop as the body loses the ability to autoregulate. The changes in blood flow start in the epicenter and spread to adjacent, undamaged tissue, which can last for as long as 24 hours and progressively worsens. Due to the differences in tissue composition, the impact of these events is greater on the interior gray matter of the spinal medulla than on the outlying white matter. Not only the blood vessels in the gray matter are damaged by the external mechanical forces, but also intact capillaries begin to leak due to the blood - spinal cord barrier (BSCB) disruption, sometimes as early as 5 minutes following the injury $[16,37,44,61]$. Edema of the spinal cord appears. The combination of vessel leakage, tissue swelling and reduction of blood circulation aggravate the physiological delivery of oxygen and nutrients to neurons causing their destruction [16]. The loss of ionic homeostasis manifested by intracellular shift of $\mathrm{Ca}^{2+}$ together with $\mathrm{Na}^{+}$and efflux of $\mathrm{K}^{+}$, appears immediately following spinal trauma [13, 16, 41, 56-58]. It is exaggerated by excessive release of neurotransmitters, especially glutamate, the substance used by nerve cells to signal each other and stimulate their activity. The flooding 


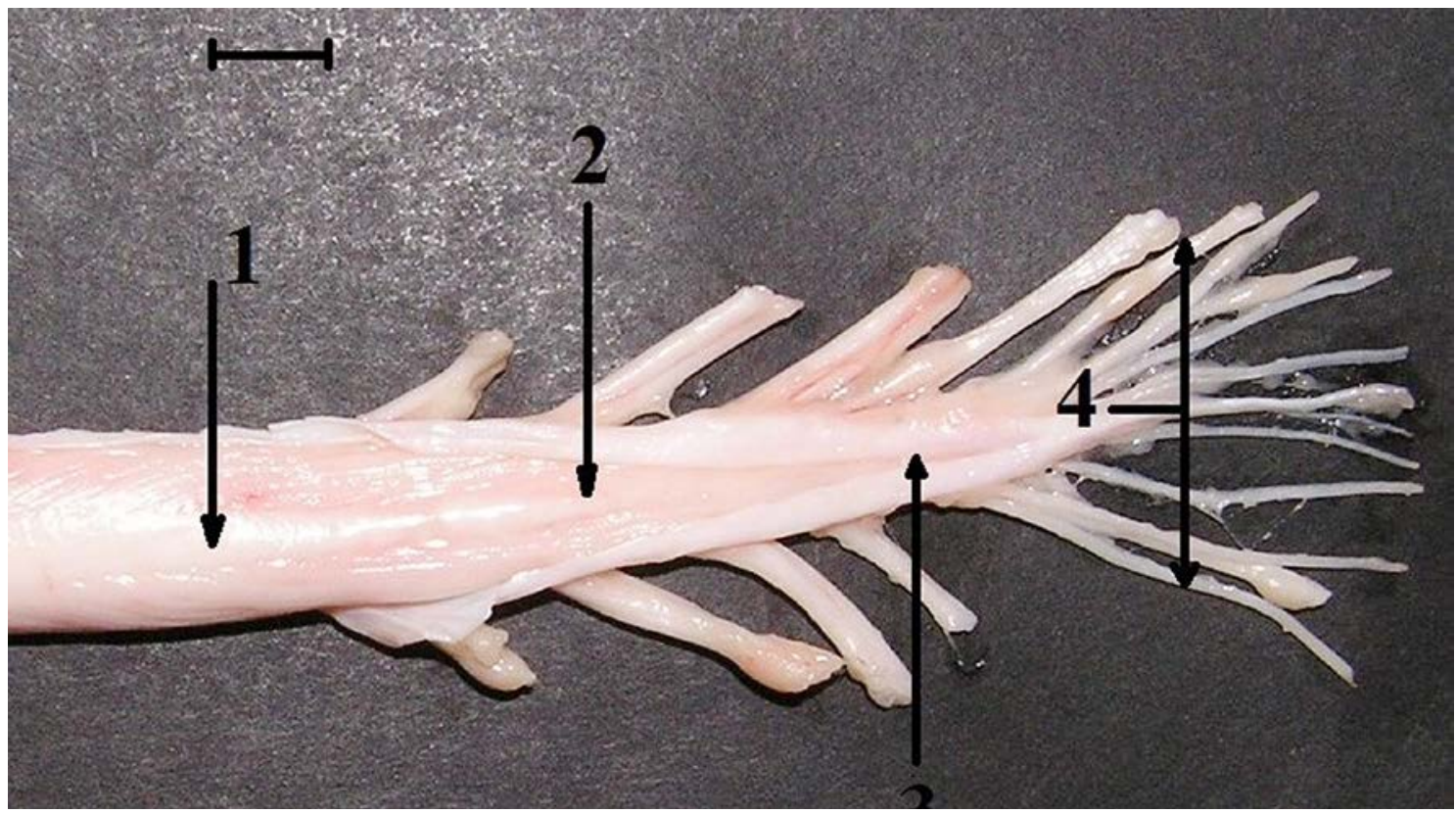

Fig. 7. An anatomical specimen of the caudal end of the spinal cord, medullary cone and cauda equina following removal from the vertebral canal and spinal dural sac

1 - spinal cord; 2 - medullary cone; 3 - terminal filament; 4 - cauda equina nerve roots. Bar $=5 \mathrm{~mm}$. (An original picture)

of the area of SCI by neurotransmitters and the loss of ionic homeostasis are central features of necrotic and apoptotic cell death $[16,41,57-59,61]$. Specifically, dysregulation of the $\mathrm{Ca}^{2+}$ ion concentration is not only a common element in cell death, but initiates a number of damaging processes including the activation of calpains, mitochondrial dysfunction and increasing free radical production [12, $13,25]$. Free radicals mediate lipid peroxidation contributing to axonal disruption and the death of both, neurons as well as glial cells. Lipid peroxidation is a self-perpetuating free radical reaction causing membrane damage leading to heart rate drop, cell lysis, the dysfunction of organelles, and further contributes to the calcium dyshomeostasis through the oxidation of membrane lipids $[13,25,28]$. When the BSCB is broken, large molecules and immune system cells enter the spinal cord tissue. This invasion triggers an inflammatory response, characterized by fluid accumulation and the influx of immune cells - neutrophils, T-cells, macrophages and monocytes $[6,53]$. The physiological function of the immune system (IS) is fighting infection and cleaning debris. However, the above mentioned response of the IS to SCI also triggers the activation of microglia and the release of cytokines - a group of messenger molecules (e.g. IL-6, IL-13, TNF- $\alpha$ ) with a distinct negative effect on the nerve cells [13, 38, 41, 44, 46, 51].
Another consequence of the immune system cells entry into the area of SCI is that inflammation accelerates the production of highly reactive forms of oxygene molecules called free radicals. They appear as by-products of normal cell metabolism. In the healthy spinal cord their numbers are too small to cause any harm. But the SCI and the subsequent wave of inflammation, signals particular cells to overproduce free radicals. Then they attack and damage molecules crucial for cell function, especially those in cell membranes, by modifying their chemical structure [5]. In the past it was supposed that the only way in which cells died in SCIs was a direct result of the traumatic event [16]. However, recent findings have revealed that cells in the damaged spinal medulla also die from a kind of programmed cell death called apoptosis [14, 25, 46, 57]. Apoptosis is a physiological cellular event that occurs in tissues and cell systems. It helps the body get rid of old or ill cells by causing them to shrink and implode. Nearby scavenger cells then engulf and remove debris. For reasons that are still unclear, SCI starts apoptosis, which kills oligodendrocytes, the cells that form myelin wrapping around axons. So apoptosis damages myelin sheets on intact axons in adjacent pathways, too $[29,44,57]$.

All of above mentioned mechanisms of secondary injury increase the area of destruction in the damaged spi- 
Table 1. Primary and secondary mechanisms involved in traumatic SCls

\begin{tabular}{|c|c|}
\hline Primary, i.e. injury phase & Secondary phase \\
\hline \multirow{4}{*}{$\begin{array}{l}\text { Compresion } \\
\text { Distraction } \\
\text { Laceration } \\
\text { Shearing mechanisms } \\
\text { Ischemia }\end{array}$} & $\begin{array}{l}\text { Vascular changes: failure of autoregulation, systemic hypotension, } \\
\text { haemorrage, blood flow reduction, impaired microcirculation, vasospasms, } \\
\text { thrombosis, BSCB disruption, edema }\end{array}$ \\
\hline & Ionic dysregulation: intracellular shift of $\mathrm{Ca}^{++}$and $\mathrm{Na}^{+}$, extracellular drift of $\mathrm{K}^{+}$ \\
\hline & $\begin{array}{l}\text { Biochemical changes: excessive release of neurotransmitters, free radicals } \\
\text { production, release of excitotoxic aminoacids (glutamate) and prostaglandins } \\
\text { lipid peroxidation }\end{array}$ \\
\hline & $\begin{array}{l}\text { Inflammation: fluid accumulation, influx of immune cells (neutrophils, T-cells, } \\
\text { macrophages, monocytes), release of cytokines }\end{array}$ \\
\hline
\end{tabular}

nal medulla. Affected axons become dysfunctional either because they are stripped of their myelin or because they are disconnected from the cranial regulatory centers [17]. Glial cells accumulate to form a scar creating a barrier to axons that could potentially regenerate. A few intact axons may remain, but they are not enough to convey meaningful information from the periphery to the brain (41).

Over weeks to months following the SCI (chronic phase), the lesion site: continues Wallerian degeneration, axon fragmentation, progressive apoptosis of the oligodendrocytes, demyelination, maturation of glial scar, cavitation of medullary tissue (syringomyelia), and stabilisation of the lesion. At about the same time the start of the reparatory processes and neuronal and axonal sprouting (supported by brain derived neurotrophic factor, i.e. BDNF) begins, but concurrently the production of neuron growth inhibitors (especially three isophorms of neurite outgrowth inhibitors, i.e. NOGO A, B, and C, myelin-associated glycoprotein, i.e. MAG, or Rho-kinase, i.e. ROCK) impede the regeneration $[7,17,29,44]$.

\section{CONCLUSION}

This review provides an overview of the current information of the etiology, pathophysiology and neurological symptomatology of spinal cord injuries in dogs.

\section{ACKNOWLEDGEMENT}

The accumulation and study of literature dealing with different aspects of spinal cord injuries as well as the prepara- tion of this paper was supported by a grant from the Agency of the Ministry of Education, Science, Research and Sport of the Slovak Republic for the Structural Funds of EU, ITMS 26220220202 and VEGA grant No. 1/0898/15.

\section{REFERENCES}

1. Aciduman, A., Belen, D., Simsek, S., 2006: Management of spinal disorders and trauma in Avicenna's Canon of medicine. Neurosurgery, 59, 397-403.

2. Adams, F., 1886: The Genuine Works of Hippocrates Translated from the Greek with a Preliminary Discourse and Annotations. Vol. 2, William Wood and Co, New York, 411 pp.

3. Adams, M. M., Hicks, A. L., 2005: Spasticity after spinal cord injury. Spinal Cord, 43, 577-586.

4. Akhtar, A.Z., Pippin, J. J., Sandusky, C. B., 2008: Animal models in spinal cord injury: a review. Rev. Neurosci., 19, 47-60.

5. Anderson, K. M., Welsh, C. J., Young, C., Levine, G. J., Kerwin, S.C., Boudreau, C.E., 2015: Acute phase proteins in cerebrospinal fluid from dogs with naturally-occurring spinal cord injury. J. Neurotrauma, 32, 1658-1665.

6. Anwar, M. A., Al Shehabi, T. S., Eid, A. I., 2016: Inflammogenesis of secondary spinal cord injury. Front. Cell. Neurosci., 10, 98. doi: 10.3389/fncel.2016.00098.

7. Borrie, S. C., Baeumer, B. E., Badtlow, C. E., 2012: The nogo66 receptor family in the intact and diseased CNS. Cell Tissue Res., 349, 105-117.

8. Breasted, J.H., 1980: The Edwin Smith Surgical Papyrus, Volume 1: Hieroglyphic Transliteration, and commentary. Univ. Chicago press, Chicago, 596 pp.

9. Brisson, B. A., 2010: Intervertebral disc disease in dogs. Vet. Clin. North Am. Small Anim. Pract., 40, 829-858. 
10. Bruce, C. W., Brisson, B. A., Gyselinck, K., 2008: Spinal fracture and luxation in dogs and cats: a retrospective evaluation of 95 cases. Vet. Comp. Orthop. Traumatol., 21, 280-284.

11. Cauzimille, L., Kornegay, J. N., 1996: Fibrocartilaginous embolism of the spinal cord in dogs: Review of 36 histologically confirmed cases and retrospective study of 26 suspected cases. J. Vet. Intern. Med., 10, 241-245.

12. David, S., Kroner, A., 2011: Repertoire of microglial and macrophage responses after spinal cord injury. Nat. Rev. Neurosci., 12, 388-399.

13. Devaux, S., Cizkova, D., Quamico, J., Franck, J., Nataf, S., Pays, L., et al., 2016: Proteomic analysis of the spatio-temporal based molecular kinetics of acute spinal cord injury identifies a time- and segment-specific window for effective tissue repair. Moll. Cell. Proteomics, 15, 2641-2670.

14. Dewey, C. W., 2008: A Practical Guide to Canine and Feline Neurology. 2nd edn., Iowa State University Press, Ames, Iowa, USA, 706 pp.

15. Ditunno, J.F., Little, J.W., Tessler, A., Burns, A.S., 2004: Spinal shock revisited: a four-phase model. Spinal Cord, 42, 383-395.

16. Dumont, R. J., Okonkwo, D. O., Verma, S., Hurlbert, R. J., Boulos, P. T., Ellegala, D. B., et al., 2001: Acute spinal cord injury, Part. I: Pathophysiologic mechanisms. Clin. Neuropharm., 24, 254-264.

17. Filbin, M. T., 2003: Myelin-associated inhibitors of axonal regeneration in the adult mammalian CNS. Nat. Rev. Neurosci., 4, 703-713.

18. Fleming, J.C., Noremberg, M.D., Ramsay, D. A., Dekalan, G. A., Marcillo, A.E., Saenz, A. D., et al., 2006: The cellular inflammatory response in human spinal cords after injury. Brain, 169, 3249-3269.

19. Fletcher, T.F., Kitchell, R.L., 1966: Anatomical studies on the spinal cord segments of the dog. Am. J. Vet. Res., 27, 1759-1767.

20. Fletcher, T.F., 2013: Spinal cord and meninges. In Evans, H. P., de Lahunta, A., (Eds.): Miller's Anatomy of the Dog. 4th edn., Elsevier, Saunders, St. Louis, USA, 589-610.

21. Gandini, G., Cizinauskas, S., Lang, J., Fatzer, R., Jaggy, A., 2003: Fibrocartilaginous embolism in 75 dogs: clinical findings and factors influencing the recovery rate. J. Small Anim. Pract., 44, 76-80.

22. Hansen, H. J., 1951: A pathologic-anatomical interpretation of disc degeneration in dogs. Acta Orthop. Scand., 20, 280-293.

23. Henke, D., Vandevelde, M., Doher, M. G., Stockli, M., Forterre, F., 2013: Correlations between severity of clinical signs and histopathological changes in 60 dogs with spinal cord in- jury associated with acute thoracolumbar intervertebral disc disease. Vet. J., 198, 70-75.

24. Jeffery, N.D., Hamilton, L., Granger, N., 2011: Designing clinical trials in canine spinal cord injury as a model to translate successful laboratory interventions into clinical practice. Vet. Rec., 168, 102-107.

25. Jeong, S. Y., Seol, D. W., Li, F. C., Chen, Q. X., 2008: The role of mitochondria in apoptosis. BMB Reports, 41, 11-22.

26. Kato, S., Kawakaza, N., Tomita, K., Murakami, H., Demura, S., Fujimaki, Y., 2008: Effects on spinal cord blood flow and neurologic function secondary to interruption of bilateral segmental arteries which supply the artery of Adamkiwicz. Spine, 33, 1533-1541.

27. Kruger, E. A., Pires, M., Ngann, Y., Sterling, M., Rubay, S., 2013: Comprehensive management of pressure ulcers in spinal cord injury. Biomaterials, 30, 2582-2590.

28. Lacroix, S., Chang, L., Rose-John, S., Tuszynski, M. H., 2002: Delivery of hyper-interleukin-6 to the injured spinal cord increases neutrophil and macrophage infiltration and inhibits axonal growth. J. Comp. Neurol., 454, 213-228.

29. Lee, J. Y., Choi, S. Y., Oh, T. H., Yune, T. Y., 2012: 17ß-estradiol inhibits apoptotic cell death of oligodendrocytes by inhibiting Rhoa-JNK3 activation after spinal cord injury. Endocrinology, $153,3815-3827$

30. Levine, G. J., Levine, J. M., Budke, C.M., Kerwin, S. C., Au, J., Vinayak, A., et al., 2009: Description and repeatability of a newly developed spinal cord injury scale for dogs. Prev. Vet. Med., 89, 121-127.

31. Mack, E.H., 2013: Neurogenic shock. Open Ped. Med. J., 7 (Suppl. 1: M4), 16-18.

32. Marketos, S.G., Skiadas, P. K., 1999: Galen. A pioneer of spine research. Spine, 24, 2358-2362.

33. McKee, W. M., Downes, C. J., Pink, J. J., Gemmill, T. J., 2010: Presumptive exercise-associated peracute thoracolumbar disc extrusion in 48 dogs. Vet. Rec., 166, 523-528.

34. McKinley, W., Santos, K., Meade, M., Brooke, K., 2007: Incidence and outcomes of spinal cord injury clinical syndromes. J. Spinal Cord Med., 30, 215-224.

35. Nakamoto, Y., Ozawa, T., Katanabe, K., Nishiya, K., Yasuda, N., Mashita, T., et al., 2009: Fibrocartilaginous embolism of the spinal cord diagnosed by characteristic clinical findings and magnetic resonance imaging in 26 dogs. J. Vet. Med. Sci., $71,171-176$

36. Navarro, R., Juhas, S., Keshavarzi, S., Juhasova, J., Motlik, J., Johe, K., et al., 2012: Chronic spinal compression model in minipigs: a systematic behavioral, qualitative, and quantita- 
tive neuropathological study. J. Neurotrauma, 29, 499-513.

37. Noble, L. J., Donovan, F., Igarashi, T., Goussev, S., Werb, Z., 2002: Matrix metalloproteinases limit functional recovery after spinal cord injury by modulation of early vascular events. J. Neurosci., 22, 7526-7535.

38. Okon, E. B., Streijger, F., Lee, J.H., Anderson, L.M., Russel, A. K., Kwon, B. K., 2013: Intraparenchymal microdialysis after acute spinal cord injury reveals differential metabolic responses to contusive spinal cord injury. J. Neurotrauma, 30, 1564-1576.

39. Olby, N., 2010: The pathogenesis and treatment of acute spinal cord injuries in dogs. Vet. Clin. N. Am. Small Anim. Pract., 40, 791-807.

40. Orr, M. B., Gensel, J. C., 2017: Interactions of primary insult biomechanics and secondary cascades in spinal cord injury: implications for therapy. Neural Regen. Res., 12, 1618-1619.

41. Oyinbo, C. A., 2011: Secondary injury mechanisms in traumatic spinal cord injury: a nugget of this multiply cascade. Acta Neurobiol. Exp., 71, 281-299.

42. Quin, W., Bauman, W.A., Cardozo, C., 2010: Bone and muscle loss after spinal cord injury: organ interactions. Ann. N. Y. Acad. Sci., 1211, 66-84.

43. Risio, L. D., Platt, S. R., 2010: Fibrocartilaginous embolic myelopathy in small animals. Vet. Clin. North Am. Small Anim. Pract., 40, 859-869.

44. Rowland, J. W., Hawryluk, G. W. J., Kwon, B., Fehlings, M. G., 2008: Current status of acute spinal cord injury pathophysiology and emerging therapies: promise on the horizon. Neurosurg. Focus, 25, E2. doi:10.317/FOC.2008.25.11.E2.

45. Sherrington, C. S., 1947: Action of the Nervous System. 2nd edn., Cambridge University Press, Cambridge, UK, 241-250.

46. Silva, N. A., Sousa, N., Reis, R. L., Salgado, A. J., 2014: From basics to clinical: a comprehensive review on spinal cord injury. Progr. Neurobiol., 114, 25-57.

47. Smith, P.M., Jeffery, N.D., 2005: Spinal shock - comparative aspects and clinical relevance. J. Vet. Intern. Med., 19, 788-793.

48. Srugo, I., Aroch, I., Christopher, M. M., Chai, O., Goralnik, I., Bdolah-Abram, I., et al., 2011: Signs and outcome in acute nonambulatory thoracolumbar disc disease in dogs. J. Vet. Intern., Med., 25, 846-855.

49. Staffeldt, K., 1963: Zur Morphogenese der pathologischanatomischen Befunde bei der "Commotio medullae spinalis". Arch. Psych. Nervenkrankheiten, 204, 328-341.

50. Stiffer, K. S., Stevenson, M. A., Sanchez, S., Barsanti, J.A., Hofmeister, E., Budsberg, S. C., 2006: Prevalence and char- acterization of urinary tract infections in dogs with surgically treated type I thoracolumbar intervertebral disc extrusion. Vet. Surg., 35, 330-336.

51. Sullivan, P. G., Krishnamurthy, S., Patel, S. P., Pandya, J. D., Rabchevsky, A. G., 2007: Temporal characterization of mitochondrial bioenergetics after spinal cord injury. J. Neurotrau$m a, 24,991-999$.

52. Šulla, I., Balik, V., Petrovičová, J., Almášiová, V., Holovská, K., Oroszová, Z., 2016: A rat spinal cord injury experimental model. Folia Veterinaria, 60, 41-46.

53. Taylor, A.R., Welsh, C.J., Young, C., Spoor, E., Kerwin, S. C., Griffin, J. F., et al., 2014: Cerebrospinal fluid inflammatory cytokines and chemokines in naturally occuring canine spinal cord injury. J. Neurotrauma, 31, 1561-1569.

54. Tomko, P., Farkaš, D., Čížková, D., Vanický, I., 2017: Longitudinal enlargement of the lesion after spinal cord injury in the rat: a consequence of malignant oedema? Spinal Cord, 55, $255-263$.

55. Waters, R. L., Adkins, R. H., Yakura, J. S., 1991: Definition of complete spinal cord injury. Spinal Cord, 29, 573-581.

56. Webb, A. A., Ngan, S., Fowler, D. J., 2010: Spinal cord injury I: a synopsis of the basic science. Can. Vet. J., 51, 485-492.

57. Wu, K. L. H., Hsu, C., Chan, J. Y. J., 2009: Nitric oxide and superoxide anion differentially activate poly(ADP-ribose) polymerase-1 and Bax to induce nuclear translocation of apoptosis inducing factor and mitochondrial release of cytochrome C after spinal cord injury. J. Neurotrauma, 26, 965-977.

58. Xu, J., Fan, G., Chen, S., Wu, Y., Xu, M., Hsu, C. Y., 1998: Methylprednisolone inhibition of TNF-KB activation after spinal cord injury in rats. Brain Res. Mol. Brain Res., 59, 135-142.

59. Yang, L., Blumberg, P. C., Jones, N. R., Manavis, J., Sarvestami, G., Ghabriel, M.N., 2004: Early expression and cellular localization of proinflammatory cytokines Interleukin- $1 \beta$, Interleukin-6, and Tumor necrosis factor- $\alpha$ in human traumatic spinal cord injury. Spine, 29, 966-971.

60. Zaki, F. A., Prata, R. G., 1976: Necrotizing myelopathy secondary to embolization of herniated intervertebral disk material in the dog. J. Am. Vet. Med. Assoc., 169, 222-228.

61. Zhou, X., He, X., Ren, Y., 2014: Function of microglia and macrophages in secondary damage after spinal cord injury. Neural Reg. Res., 9, 1787-1795.

Received February 14, 2018

Accepted April 12, 2018 